\title{
ANÁLISES FÍSICO-QUÍMICAS DE ALIMENTOS: UMA PROPOSTA PARA A COMPLEMENTAÇÃO DA FORMAÇÃO DO ESTUDANTE TÉCNICO EM QUÍMICA DO MUNICÍPIO DE SETE LAGOAS - MG
}

\author{
PHYSICAL-CHEMICAL ANALYSIS OF FOODS: A PROPOSAL TO \\ COMPLEMENT THE TECHNICAL TRAINING OF STUDENTS IN \\ CHEMISTRY IN THE CITY OF SETE LAGOAS-MG
}

Gabriel Dias dos Reis ${ }^{1}$; Christiano Vieira Pires $^{2}$

\begin{abstract}
RESUMO
A ciência e tecnologia de alimentos tem se desenvolvido como uma importante ciência aplicada e inclui o estudo das características químicas, físicas e biológicas dos alimentos, além dos processos de seleção da matéria-prima, processamento, conservação e distribuição. A industrialização de alimentos pode contribuir consideravelmente na melhoria da dieta de um país e no estado nutricional de seus habitantes. Porém, o alimento disponibilizado para venda no mercado deve apresentar características adequadas para o consumo de modo a garantir a segurança alimentar. Essa segurança está baseada nos Padrões de Identidade e Qualidade (PIQ) dos alimentos e apresenta diversos parâmetros para verificação da qualidade. Dentre os parâmetros avaliados na qualidade de alimento processados temos as características físico-químicas que incluem a composição centesimal de alimentos. O presente trabalho teve como principal objetivo capacitar estudantes técnicos em química do município de Sete Lagoas na realização de análises físico-químicas de alimentos, através de aulas realizadas na Universidade Federal de São João del-Rei - Campus Sete Lagoas. Foram obtidos resultados que expressam um bom desenvolvimento dos estudantes envolvidos nas atividades, o que contribui para o aumento de mão de obra qualificada a ser absorvida pelas indústrias de alimentos da região de Sete Lagoas.
\end{abstract}

Palavras-chave: Alimentos. Análises. Química. Extensão. Indústria.

\begin{abstract}
The science and food technology has developed as an important applied science and includes the study of the chemical, physical and biological properties of foods, in addition to the selection process of the raw material, processing, storage and distribution. The industrialization of food can contribute considerably in improving the diet of a country and the nutritional status of its inhabitants. However, the food available for sale in the market should possess characteristics suitable for consumption to ensure food security. This security is based on the Standards of Identity and Quality of food and presents various parameters for quality check. Among the parameters evaluated on the quality of processed food have the physicochemical characteristics including chemical composition of foods. This study aimed to train students in technical chemistry city of Sete Lagoas in performing physical and chemical analysis of food through classes held at the Federal University of São João del-Rei - Campus Sete Lagoas. Results were obtained that express a good development of the students involved in the activities, which contributes to the increase of skilled labor to be absorbed by the food industry in the region of Sete Lagoas.
\end{abstract}

Keywords: Food. Analysis. Chemistry. Extension. Industry.

\footnotetext{
${ }^{1}$ Bolsista PIBEX-UFSJ, Universidade Federal de São João del Rei, Campus de Sete Lagoas - MG. Email: gabrieldias.ufsj@yahoo.com.br

${ }_{2}^{2}$ Professor da Universidade Federal de São João del Rei, Campus de Sete Lagoas - MG. Email: christiano@ufsj.edu.br
} 


\section{INTRODUÇÃO}

\section{O ENSINO DE QUÍMICA NO BRASIL: O DESAFIO DE SE CONSTRUIR UM MODELO INCLUSIVO}

A química tem como objetos de investigação os materiais, as substâncias, suas propriedades, sua constituição e suas transformações. No centro de todas essas investigações certamente encontram-se os materiais e as substâncias, conforme afirma Mortimer (2000).

Segundo Mortimer (2000), é útil distinguir três aspectos do conhecimento químico: fenomenológico, teórico e representacional. O aspecto fenomenológico diz respeito aos fenômenos de interesse da química, sejam aqueles concretos e visíveis, como a mudança de estado físico de uma substância, sejam aqueles a que temos acesso apenas indiretamente, com o as interações radiação, matéria, luz, não provocam um efeito visível, mas que podem ser detectadas na espectroscopia. Os fenômenos da química também não se limitam àqueles que podem ser reproduzidos em laboratório. Falar sobre o supermercado, sobre o posto de gasolina é também uma ocorrência fenomenológica. Neste caso, o fenômeno está materializado na atividade social. É isso que vai dar significação para a Química do ponto de vista do aluno. São as relações sociais que ele estabelece através da ciência que mostram que a Química está na sociedade, no ambiente. A abordagem do ponto de vista fenomenológico também pode contribuir para promover habilidades específicas tais como controlar variáveis, medir, analisar resultados, elaborar gráficos, etc. O aspecto teórico relaciona-se a informações de natureza atômico-molecular, envolvendo, portanto, explicações baseadas em modelos abstratos e que incluem entidades não diretamente perceptíveis, como átomos, moléculas, íons, elétrons, etc. Os conteúdos químicos de natureza simbólica estão agrupados no aspecto representacional, que compreende informações inerentes à linguagem química, como fórmulas e equações químicas, representações dos modelos, gráficos e equações matemáticas.

A maioria dos currículos tradicionais e dos livros didáticos enfatiza sobremaneira o aspecto representacional, em detrimento dos outros dois. A ausência dos fenômenos nas salas de aula pode fazer com que os alunos tomem por "reais" as fórmulas das substâncias, as equações químicas e os modelos para a matéria. É necessário, portanto, que os três aspectos compareçam igualmente. A produção do conhecimento em Química resulta sempre de uma dialética entre teoria e experimento, pensamento e realidade, Mesmo porque não existe uma atividade experimental sem uma possibilidade de interpretação. Ainda que o aluno não conheça a teoria científica necessária para interpretar determinado fenômeno ou resultado 
experimental ele o fará com suas próprias teorias implícitas, suas ideias de senso comum, pois todo processo de compreensão é ativo.

De acordo com Mortimer (2000), para que a interpretação do fenômeno ou resultado experimental faça sentido para o aluno, é desejável manter essa tensão entre teoria e experimento, percorrendo constantemente o caminho de ida e volta entre os dois aspectos. $\mathrm{O}$ aspecto representacional também resulta dessa tensão, fornecendo as ferramentas simbólicas para representar a compreensão resultante dos processos de idas e vindas entre teoria e experimento.

A necessidade de revisão dos pressupostos da Educação das Ciências, demonstrando, sobretudo, os limites da dimensão técnico-experimental vem sendo evidenciada por estudos nacionais e internacionais por meio de argumentos consistentes. Esse imperativo inclui, certamente, a Educação Química.

Todavia, a disciplina Química só passou a ser regularmente ministrada no ensino secundário brasileiro com a Reforma Francisco Campos (1931), objetivando a apropriação de conhecimentos específicos, despertando o interesse científico do educando por meio da relação entre a Química e o cotidiano. Com a LDB de 1971, o caráter do ensino de Química passou a ser acentuadamente técnico-científico. Hoje se recomenda que a Química seja reconhecida nos alimentos e medicamentos, nas fibras têxteis e nos corantes, nos materiais de construção e nos papéis, nos combustíveis e nos lubrificantes, nas embalagens e nos recipientes. Isto é, remete-nos à vida das pessoas e à manutenção da própria vida. Certamente, as escolas de ensino médio planejam, concebem e vivenciam suas práticas influenciadas pelos documentos oficiais, fazendo recontextualizações e oferecendo formas de resistência ou de aquiescência, conforme relatado em Tosta (2005).

De acordo com Rosa (2005) a alfabetização científica, atualmente em debate significaria, em termos de participação em práticas culturais, acesso à informação e aos postos de trabalho mais qualificados e melhor remunerados, o que possibilitaria, também, a superação da pobreza e da exclusão. Para tal, não bastam anos a mais de escolarização e ações educacionais para garantir níveis satisfatórios de alfabetismo. É preciso mais. Os resultados da escolarização em termos de aprendizagem ainda são insuficientes. Faz-se necessário melhorar o desempenho dos sistemas de ensino e elevar a qualificação da força de trabalho em todos os níveis, tendo em vista a participação nos setores de ponta da economia mundializada e o fortalecimento das instituições democráticas.

O modelo de crescimento econômico possibilitou a existência de riqueza e fartura nunca vista antes no mundo. Por outro lado, a miséria, a degradação ambiental e a poluição 
aumentam dia-a-dia, em um descompasso cruel. A idéia do desenvolvimento sustentável, conciliando o desenvolvimento econômico à preservação ambiental e gerando o fim da pobreza no mundo, surge nesse contexto, propondo melhoria da qualidade de vida e das condições de sobrevivência dos seres.

É sob este aspecto que é preciso pensar a Química para o desenvolvimento sustentável e inclusão social. Afinal, a importância da Química como Ciência central é indiscutível, e sua inserção nas políticas de desenvolvimento da sociedade brasileira é fundamental: a Química permeia grande parte do estado da arte de grande parte dos avanços científicos e tecnológicos nacionais. Em Bolzani (2005), é evidenciado que alfabetizar cientificamente, promovendo o desenvolvimento e a inclusão social, é o papel dos educadores químicos para o resgate de grande contingente de cidadãos brasileiros excluídos.

Há uma necessidade da incorporação da formação de atitudes de responsabilidade pessoal e social na educação científica e tecnológica, buscando um ensino de melhor qualidade em Ciência e Tecnologia. Entendemos que é a partir do trabalho coletivo e de parcerias colaborativas entre professores e estudantes universitários, juntamente com os professores das Escolas Básicas, que se torna possível propor inovações didático-pedagógicas no âmbito do ensino/aprendizagem da Química.

\section{CIENCIA E TECNOLOGIA DE ALIMENTOS: UMA PROPOSTA PARA A INCLUSÃO E COMPLEMENTAÇÃO DA FORMAÇÃO DOS ESTUDANTES DE CURSOS TÉCNICOS EM QUÍMICA}

A Ciência de Alimentos inclui o estudo das características físicas, químicas e biológicas dos alimentos. A Tecnologia de Alimentos inclui a sequência de operações desde a seleção da matéria-prima até o processamento, preservação e distribuição. Assim, a Ciência e Tecnologia de alimentos tem se desenvolvido como uma importante ciência aplicada, responsável pelos processos de processamento dos alimentos, conforme encontrado em Gava (2008).

A industrialização dos produtos agropecuários pode contribuir consideravelmente na melhoria da dieta de um país e no estado nutricional dos seus habitantes. A amplitude dessa contribuição depende de diversos fatores, como a existência de uma agricultura desenvolvida que possa aplicar uma tecnologia avançada e do nível econômico e poder aquisitivo da população. A tecnologia alimentar é o vínculo entre a produção e o consumo dos alimentos e ocupa-se de sua adequada manipulação, elaboração, preservação, armazenamento e 
comercialização. Para que se possa alcançar um bom rendimento, a tecnologia de alimentos deve estar intimamente associada aos métodos e progressos da produção agrícola e aos princípios e práticas da nutrição humana.

Ainda, segundo Gava (2008), a indústria de alimentos ocupa uma posição estratégica, atuando como intermediária entre a produção agrícola e a distribuição de alimentos processados. A indústria brasileira de alimentos é uma das indústrias de transformação que mais tem crescido e um dos setores econômicos que apresenta maior potencial de crescimento.

Independentemente das crises é um segmento que está sempre crescendo, porque atende a uma das necessidades básicas da população.

De acordo com dados encontrados em Gava (2008), segundo o IBGE (2007), o Brasil tinha em 2004, na fabricação de produtos alimentícios e bebidas, 20.934 empresas, com 1.276.313 pessoas ocupadas e receita líquida de vendas de $\mathrm{R} \$ 222$ bilhões.

Ainda, segundo Gava (2008), de acordo com a ABIA -Associação Brasileira das Indústrias da Alimentação- (2006), em 2005 o setor empregava 1,015 milhão de trabalhadores com 41.600 empregados por ano e 40.700 empresas formais.

Observa-se, assim a importância da indústria de alimentos, dentro do agronegócio brasileiro e seu papel relevante na pauta de exportações, contribuindo positivamente na balança comercial brasileira.

Nesse sentido, é necessário intervir de maneira positiva na atual estrutura curricular de diversos tipos de formação de profissionais da Química para garantir que a ampliação dos recursos intelectuais destes, sejam suficientes para a atuação em diversos sistemas. Um exemplo dessa intervenção é a utilização dos conceitos de Ciência e Tecnologia de Alimentos no processo de formação do estudante dos cursos técnicos em química.

\section{A FORMAÇÃO DO TÉCNICO EM QUÍMICA NO MUNICÍPIO DE SETE LAGOAS- MG}

O município de Sete Lagoas é um dos maiores centros produtores de ferro gusa do estado de Minas Gerais, e também apresenta uma substancial participação econômica com a indústria automobilística. Devido a essa característica associada à economia local, a tendência de formação profissional na região sempre priorizou aspectos orientados a esses dois tipos de indústria. Porém, com o crescimento da cidade e a instalação de indústrias de outros segmentos, houve a necessidade de contratação de mão de obra qualificada proveniente de 
outras regiões do estado e do país. Nesse sentido, as indústrias alimentícias tiveram que se adaptar a situação local para suprimir o déficit por profissionais com conhecimentos técnicos nessa área. Ao se avaliar também, a grade curricular do curso técnico em química oferecido pela Escola Técnica Municipal de Sete Lagoas, percebe-se a ausência de uma disciplina que aborde especificamente as principais análises físico-químicas de alimentos.

Dessa maneira a capacitação de estudantes técnicos em química da região de Sete Lagoas, em análises físico-químicas de alimentos, se justifica como uma qualificação complementar desses, e, supre a necessidade das indústrias alimentícias locais por colaboradores com tal qualificação. Além disso, promove a incorporação da disciplina análises de alimentos no currículo desses estudantes, ampliando o conhecimento científico e percepção crítica sobre a importância das determinações analíticas laboratoriais nos aspectos envolvidos com o processamento de alimentos. O desenvolvimento das atividades permite também, uma maior aproximação da Universidade Federal de São João del-Rei - Campus Sete Lagoas com a comunidade local, favorecendo parcerias de ensino e pesquisa a partir de atividades de extensão numa proposta de diálogo permanente com a comunidade local.

\section{OBJETIVOS}

O presente trabalho teve como objetivo capacitar estudantes de nível técnico, na realização de análises físico-químicas de alimentos, segundo as principais leis, decretos, resoluções, portarias e outros instrumentos técnicos legais. Além disso, a partir do trabalho realizado objetivou-se fornecer profissionais capacitados em análises físico-químicas de alimentos às indústrias alimentícias de Sete Lagoas e região.

\section{MATERIAIS E MÉTODOS}

Foi realizada a seleção de 20 estudantes do curso técnico em Química da Escola Técnica Municipal de Sete Lagoas, no mês de maio de 2012. Essa seleção foi realizada pela coordenação do projeto e os critérios de seleção foram entrevista individual e análise do coeficiente de rendimento de cada estudante.

A partir dessa seleção, foram iniciadas as atividades do curso de "Análises FísicoQuímicas de Alimentos", nas dependências da Universidade Federal de São João del-Rei. O curso ministrado foi desenvolvido a partir de atividades teóricas e práticas. As atividades 
teóricas e práticas foram desenvolvidas no período de 12 meses, com encontros semanais de 5 horas de duração.

Para as aulas teóricas expositivas foram utilizadas recursos tecnológicos como datashow e outras ferramentas computacionais.

As aulas práticas foram desenvolvidas nos laboratórios: Ciência e Tecnologia de Alimentos I, Embalagens de Alimentos e Química Geral I, na Universidade Federal de São João del-Rei. Para a realização das análises previstas no conteúdo programático do curso foram utilizados equipamentos de laboratório (estufas, muflas, destiladores de nitrogênio, digestores, banho-maria, etc), vidrarias (béqueres, erlenmeyers, balões volumétricos, pipetas, buretas, placas de petri, etc), reagentes (ácido sulfúrico, sulfato cuproso, hidróxido de sódio, ácido clorídrico, etc) e alimentos (produtos cárneos, produtos lácteos, produtos de panificação, bebidas alcoólicas e não alcoólicas, entre outros).

O curso "Análises Físico-Químicas de Alimentos" foi elaborado a partir da consulta aos métodos oficiais para análises de Alimentos descritos no Codex Alimentarius, nos manuais de Análise de Alimentos do Instituto Adolf Lutz, na literatura especializada e em artigos científicos de importância para a área de Ciência dos Alimentos. O conteúdo programático, as atividades realizadas e o período de realização destas, estão descritos no Quadro 1.

\section{RESULTADOS E DISCUSSÃO}

Os estudantes do curso técnico em Química da Escola Técnica Municipal de Sete Lagoas realizaram as atividades propostas interagindo com os conteúdos apresentados de maneira multidisciplinar. Dessa forma, interligaram conteúdos curriculares desenvolvidos nas disciplinas básicas do curso técnico em Química, para a formulação dos conceitos aplicados às análises físico-químicas de alimentos. Esse processo resultou na construção de uma nova percepção dos estudantes acerca das possibilidades de atuação do profissional técnico em química, a partir da elucidação da Ciência dos Alimentos em seu contexto social e tecnológico.

As propostas curriculares para o ensino de ciência na perspectiva ciência, tecnologia e sociedade (CTS) possuem como principal meta preparar os alunos para o exercício da cidadania, conforme encontrado em Mortimer (2001). 


\section{Revista}

\section{Triângulo}

A execução de procedimentos analíticos é de fundamental importância para estudantes de cursos técnicos em química, pois o mercado de trabalho absorve tais profissionais para que eles possam atuar em laboratórios de controle de qualidade, pesquisa, desenvolvimento e meio ambiente. O curso “Análises Físico-Químicas de Alimentos” permitiu que os estudantes em formação técnica executassem procedimentos analíticos em laboratórios com equipamentos modernos e estrutura similar à recomendada para os laboratórios das indústrias alimentícias.

As indústrias de alimentos de Sete Lagoas e região foram beneficiadas a partir da formação complementar do estudante técnico em química em análises de alimentos, pois a qualificação necessária para atuação nesses sistemas produtivos é de fundamental importância para que os produtos elaborados sejam comercializados segundo as legislações responsáveis pela segurança alimentar.

É necessário que o alimento produzido pelas indústrias apresente características físicas, químicas e microbiológicas que estejam de acordo com os parâmetros estabelecidos pelas legislações. Sendo assim, as análises físico-químicas são de grande importância na avaliação da qualidade dos alimentos, pois, a partir delas obtêm-se informações qualitativas e quantitativas dos nutrientes presentes nos alimentos, dos aspectos toxicológicos e até mesmo microbiológicos. Diversos índices obtidos por esses métodos expressam a segurança do alimento (GOMES e OLIVEIRA, 2011: 11).

A realização do projeto contribuiu para a consolidação da Universidade Federal de São João del-Rei no município de Sete Lagoas, a partir das atividades de extensão, que permitiram uma comunicação direta com a comunidade local e a participação em seus processos de construção do conhecimento técnico-científico.

Bolzani (2005) propõe a utilização da Química para o desenvolvimento sustentável e inclusão social. Afinal, a importância da Química como Ciência central é indiscutível, e sua inserção nas políticas de desenvolvimento da sociedade brasileira é fundamental: a Química permeia grande parte do estado da arte de grande parte dos avanços científicos e tecnológicos nacionais. Alfabetizar cientificamente, promovendo o desenvolvimento e a inclusão social, é nosso papel como educadores químicos para o resgate de grande contingente de cidadãos brasileiros excluídos. 


\section{CONSIDERAÇÕES FINAIS}

A geração de novas oportunidades educacionais destinadas à capacitação de estudantes técnicos é de fundamental importância no atual contexto econômico brasileiro. Tais atividades proporcionam uma articulação efetiva entre as indústrias, escolas de formação técnica e superior e a sociedade, garantindo oportunidades de inclusão do cidadão integrado nesse processo. Sendo assim, o curso “Análises Físico-Químicas de Alimentos” contribuiu para a complementação da formação do estudante técnico em Química do município de Sete Lagoas, disponibilizou profissionais qualificados para as indústrias alimentícias locais e inseriu a Universidade Federal de São João del-Rei-Campus Sete Lagoas em um processo permanente de participação no desenvolvimento da comunidade local.

\section{AGRADECIMENTOS}

PROEX-UFSJ, FAPEMIG, Escola Técnica Municipal de Sete Lagoas e Multitécnica Industrial LTDA.

\section{REFERÊNCIAS}

BOLZANII, V. S. Editorial para a 28. ${ }^{\text {a }}$ Reunião Anual da Sociedade Brasileira de Química. 2005. Disponível em: www.sbq.org.br/28ra/editorial.php

GAVA, A.J. Tecnologia de Alimentos: princípios e aplicações. 2. ed. São Paulo: Nobel, 2008. .Introdução às análises de alimentos. In: GOMES, J. C.; OLIVEIRA, G.F. Análises Físico-Químicas de Alimentos. Viçosa: UFV, 2011.

MORTIMER et al. Tomada de decisão para ação social responsável no ensino de Ciências, Ciência \& Educação, v. 7, p. 95-111, 2001.

MORTIMER, E. F.; MACHADO, A. H.; ROMANELLI, L. I. A proposta curricular de Química do Estado de Minas Gerais, Química Nova, v. 23, p. 273-283, 2000.

ROSA, M. I. P. O lugar da Química na escola - movimentos constitutivos da disciplina no cotidiano escolar. Ciência \& Educação. Faculdade de Ciências - UNESP, v. 11, n. 2, 2005. 
TOSTA, A. H. O lugar da Química na escola - movimentos constitutivos da disciplina no cotidiano escolar. Ciência \& Educação. Faculdade de Ciências - UNESP, v. 11, n. 2, 2005.

\section{Quadro 1}

Conteúdo programático, atividades realizadas no curso "Análises Físico-Químicas de Alimentos" e período utilizado para a realização das atividades propostas.

\begin{tabular}{|l|c|}
\hline \multicolumn{1}{|c|}{ Conteúdo programático e atividades realizadas } & Período de realização \\
\hline - Aulas teóricas: Fundamentos de Química Analítica, preparo e & \\
padronização de soluções, amostragem e preparo de amostras, & \\
segurança em laboratorio. & 2 meses \\
- Aulas Práticas: Preparo de soluções, padronização de & \\
soluções, preparo de amostras, técnicas de segurança em \\
laboratório.
\end{tabular}




\begin{tabular}{|l|l|}
\hline vinagres, refrigerantes e sucos. & \\
\hline - Aulas teóricas: Fundamentos de análises instrumentais para & \\
alimentos, refratometria, espectrofotometria e colorimetria. & \multirow{2}{*}{1 mês } \\
- Aulas práticas: Determinação de cor em produtos cárneos; & \\
sólidos solúveis ( ${ }^{\circ}$ Brix) em mel; textura em pães; células & \\
somáticas em leite cru; atividade de água em doce de leite. & \\
\hline
\end{tabular}

Fonte: Dos autores.

RECEBIDO EM: 20/09/2013

APROVADO EM: 21/09/2015 